\title{
Percolated conductive polyaniline-clay nanocomposite in polyvinyl chloride through the combined approach porous template and self-assembly
}

\author{
J. D. Sudha*, S. Sivakala, C. K. Chandrakanth, K. S. Neethu, K. N. Rohini, R. Ramakrishnan \\ Chemical Sciences and Technology Division, National Institute for Interdisciplinary Science and Technology (NIIST), \\ CSIR, 695019 Thiruvananthapuram, India
}

Received 31 July 2013; accepted in revised form 8 October 2013

\begin{abstract}
In this paper, we are reporting a novel strategy for the preparation of conductive polyaniline-clay nanocomposite in Polyvinylchloride (PVC) matrix by admicellar emulsion polymerization using a low cost renewable resource based surfactant cum dopant. The highly oriented percolated network of polyaniline-clay nanocomposite in PVC matrix was revealed from the studies made by scanning electron microscopy (SEM) and atomic force microscopy (AFM). Fourier transform infrared spectroscopy (FTIR) results suggested that porous template was formed by the noncovalent interactions among the hydroxyl groups present in the nanoclay edges and the chloride ions present in PVC matrix. Here, the bio-based surfactant, 4-hydroxy-2-pentadecyl benzene-1-sulphonic acid (PDPSA) performed multiple roles of dopant, emulsifier and soft template during the polymerization of anilinium ${ }^{+} \mathrm{PDPSA}^{-}\left(\mathrm{An}^{+} \mathrm{PDPSA}^{-}\right)$in PVC-clay matrix. The prepared composite exhibited electrical conductivity $\left(\sigma_{\mathrm{dc}}\right)$ of $4.8 \cdot 10^{-2} \mathrm{~S} / \mathrm{cm}$ and electromagnetic interference shielding efficiency (EMI SE) of $55.2 \mathrm{~dB}$ suggesting it as a prospectable candidate for the encapsulation of electronic devices in high technological applications.
\end{abstract}

Keywords: nanocomposites, admicellar emulsion polymerization, conducting polymers

\section{Introduction}

Nanostructured electrically conducting polymer composites are explored largely due to their combined properties of the conventional polymers such as ease of processability, low density, environmental stability and corrosion resistance with electrical properties of conducting polymers. Literature reveals that conducting polymers with nanoscale morphologies including tubes, wires and fibres can be constructed by either self-assembly $[1,2]$ or template approach [3-6] for the fabrication of electronic devices such as batteries, capacitors, light emitting diodes and sensors. Development of polyaniline (PANI) wires using self-assembled micelle of amphiphilic dopant by self-assembly approach has been reported earlier [7]. Carswell et al. [8] and other authors [9-11] have used adsorbed surfactants as templates for the synthesis of morphologically controlled PANI and polypyrrole nanowires on flat surfaces. Babu et al. [12] proposed solvent directed self-assembly of $\pi$-gelators for the preparation of hierarchically aligned orthophenylene vinylene amide nanofibers on polystyrene matrix. Polystyrene micro porous materials with porosity ranging from micro to nano range prepared through the sublimation of solvent by Guenet and coworkers $[13,14]$. A new way to pattern conjugated polymers with nanoscale dimensions on a solid surface has been described by admicellar polymerization (AP) [15]. AP can be visualized as a technique analogous to emulsion polymerization where the adsorbed bilayered surfactant aggregates are used as tem-

\footnotetext{
${ }^{*}$ Corresponding author, e-mail: sudhajd2001@yahoo.co.in (C) BME-PT
} 
plates on various surfaces. Interactions between polymers and surfactants in the bulk have been extensively reviewed due to its relevance in many industrial applications.

Small diameter, high aspect ratio, excellent conductivity, and high thermo-mechanical stability are required to create conductive composites for high performance applications. Researchers have shown that nanocomposites with different morphologies can be produced by tuning of polymer-clay interactions [16-21]. Synthesis of conducting polyanilineclay nanocomposites $(\mathrm{PCN})$ is receiving attention in this respect since they are associated with the above mentioned novel properties. We have reported earlier that 'PDPSA' derived from cashew nut shell liquid played multiple role of intercalating agent, structure directing agent and dopant during the formation of nanostructured PCNs $[14,22]$. In the present work, we are reporting a novel strategy for the preparation of highly oriented percolated patterns of PCN in PVC matrix (PVCPCN) using a combined mechanism of porous template and self-assembly approach. Onset of percolation threshold concentration (PTC) was manifested from the morphological studies in combination with electrical conductivity measurements. The entanglement among the clay, PANI and PVC in PVCPCN composite was manifested from rheological measurements and FTIR. Electrical conductivity, thermal properties and EMI SE of these composites were evaluated.

\section{Experimental}

\subsection{Materials}

Bentonite clay with cation exchange capacity of $80 \mathrm{meq} / 100 \mathrm{~g}$ and a chemical formula of $(\mathrm{Na}, \mathrm{Ca})_{0.33}$ $\left(\mathrm{Al}_{1.67} \mathrm{Mg}_{0.33}\right) \mathrm{Si}_{4} \mathrm{O}_{10}(\mathrm{OH})_{2} \cdot n \mathrm{H}_{2} \mathrm{O}$ was purchased from Loba Chemie, Bombay, India. Aniline monomer, methyl alcohol and ammonium persulphate (APS) obtained from s.d.fine chem limited, Bombay, India. PDPSA was prepared through the sulphonation of 3-pentadecyl phenol, (cashew export promotion council, India) based on the procedure reported earlier [8]. Polyvinyl chloride [molecular weight: $M_{\mathrm{n}}=$ $\left.61500, M_{\mathrm{w}}=88500, \mathrm{PDI}=1.4\right]$ was procured from Nikunj enterprises, Bombay, India. Aniline was vacuum distilled prior to use.

\subsubsection{Preparation of $\mathrm{An}^{+} \mathrm{PDPSA}^{-}$micelle}

$\mathrm{An}^{+} \mathrm{PDPSA}^{-}$micelles were prepared by mixing stoichiometric proportion of $0.025 \mathrm{~g}$ of aniline $\left(2.9 \cdot 10^{-3}\right.$ mole $)$ and $0.011 \mathrm{~g}\left(2.9 \cdot 10^{-3}\right.$ mole $)$ of PDPSA in water at $60^{\circ} \mathrm{C}$ for $1 \mathrm{hr}$.

\subsubsection{Preparation of PVC-Clay dispersion}

$2.5 \mathrm{~g}$ of PVC in $250 \mathrm{~mL}$ chloroform was taken in a $500 \mathrm{~mL}$ three-necked round bottomed flask and was fitted with a mechanical stirrer and a reflux condenser. Then it was heated with stirring under reflux for $1 \mathrm{hr}$ until the complete dispersion of PVC. Clay dispersion was prepared separately by stirring $0.025 \mathrm{~g}$ clay in $25 \mathrm{~mL}$ water at $60^{\circ} \mathrm{C}$ for $4 \mathrm{hrs}$. Then the prepared clay dispersion was added drop wise to the PVC dispersion and stirred well for getting a homogeneous system.

\subsubsection{Preparation of electrically conductive PVCPCN}

Electrically conductive PCN percolates in PVC matrix were prepared by admicellar polymerization of ' $\mathrm{An}^{+} \mathrm{PDPSA}^{-}$' in $\mathrm{PVC}$ - clay dispersion using APS as oxidant initiator. $100 \mathrm{~mL}$ of $10^{-3} \mathrm{M}$ solution of $\mathrm{An}^{+} \mathrm{PDPSA}^{-}$was added drop wise to the PVC-clay dispersion and stirred for $2 \mathrm{hrs}$. The mixture was then cooled down to $0^{\circ} \mathrm{C}$ by keeping in an ice bath and a solution of APS ( 0.03 mole) dissolved in $50 \mathrm{~mL}$ water was added drop wise to initiate the polymerization. Reaction continued for another 3 to $4 \mathrm{hrs}$. The emeraldine green colored conductive composite formed was isolated by precipitating from methanol. It was then filtered, washed several times with methanol and dried in a vacuum oven for 3 days at $60^{\circ} \mathrm{C}$. The purified product is designated as PVCPCN. The procedure was repeated for developing composites with varying weight percentage of conductive PCN and the details are depicted in Table 1.

The same procedure is repeated for the preparation of composites without clay and was designated as PVCPN and the details were given in Table 1. PANICN and PANI-PDPSA were prepared as per the procedure reported earlier [22].

\subsection{Fabrication of conductive films}

Electrically conductive PVCPCN and PVCPN composites were cast into film from an electrically heated film making press. The compression moulded samples (thickness $10 \mathrm{~mm}$, planar area $5.2 \cdot 10^{-4} \mathrm{~m}^{2}$ ) were prepared by keeping the composites at $100^{\circ} \mathrm{C}$ for five minutes under pressure. Then films were allowed to cool at room temperature and measurements were made after keeping for $24 \mathrm{hr}$. 
Table 1. Electrical conductivity and EMI SE of PVCPN and PVCPCN composites

\begin{tabular}{|l|c|c|c|c|}
\hline \multicolumn{1}{|c|}{ Sample code } & wt\% of PANI & $\mathbf{w t} \%$ of clay & $\begin{array}{c}\text { Conductivity } \\
{[\mathbf{S} / \mathbf{c m}]}\end{array}$ & EMI SE $[\mathbf{d B}] \mathbf{a t} \mathbf{1 0} \mathbf{~ G H z}$ \\
\hline PVC & 0.0 & - & - & - \\
\hline PANI-PDPSA & 100.0 & - & 3.5 & - \\
\hline PVCPN 1 & 5.0 & - & $2.33 \cdot 10^{-4}$ & 8.1 \\
\hline PVCPN 2 & 7.5 & - & $2.45 \cdot 10^{-2}$ & 14.8 \\
\hline PVCPN 3 & 10.0 & - & $2.20 \cdot 10^{-2}$ & 35.3 \\
\hline PVCPCN 1 & 2.5 & 10 & $8.46 \cdot 10^{-6}$ & 56.7 \\
\hline PVCPCN 2 & 5.0 & 10 & $4.26 \cdot 10^{-4}$ & 66.0 \\
\hline PVCPCN 3 & 7.5 & 10 & $4.73 \cdot 10^{-4}$ & 73.2 \\
\hline PVCPCN 4 & 10.0 & 10 & $4.58 \cdot 10^{-4}$ & \\
\hline
\end{tabular}

\subsection{Characterization techniques}

UV-Vis absorption spectra of the PVCPCN composites were studied using UV-Vis spectrophotometer [Shimadzu model 2100, Japan] in the range of 300-1100 nm. FT-IR measurements of the composites were made using fully computerized Nicolet impact 400D FT-IR spectrophotometer (Czech Republic, EU). X-ray diffraction studies were done using powder X-ray diffractometer (Philips X'pert Pro, Netherlands) with $\mathrm{CuK}_{\alpha}$ radiation $(\lambda \sim$ $0.154 \mathrm{~nm}$ ) employing $X^{\prime}$ celarator detector and monochromator at the diffraction beam side. Thin films casted on glass plates were used employing standard sample holder. Electrical conductivity $\left(\sigma_{\mathrm{dc}}\right)$ of films was measured using the standard spring loaded pressure contact four probe conductivity meter supplied by Keithley (Germany) as per the standard procedure ASTM F 43-99. The conductivity $\left(\sigma_{0}\right)$ was calculated using Van der Pauw relation $\sigma_{0}=$ $[\ln 2 /(\pi \cdot d)] \cdot(I / V)$. Where $d$ is the thickness of the film, $I$ is the current and $V$ is the voltage. Morphology of the hard and soft template formation was observed under AFM. Images were recorded under ambient conditions using Ntegra multimode Nanoscope IV (Netherlands) operating in the tapping mode regime. Micro fabricated silicon cantilever tips (MPP-11100-10) with a resonance frequency of $284-299 \mathrm{kHz}$ and a spring constant of $20-80 \mathrm{Nm}^{-1}$ were used. The scan rate varied from 0.5 to $1.5 \mathrm{~Hz}$. Complementary studies were made using scanning electron microscope (SEM, JEOL make, model JSM $5600 \mathrm{LV}$,Germany) at $15 \mathrm{kV}$ accelerating voltage. ESEM experiments with the dispersion of PVC-clay were carried out using the FEG Quanta ESEM instrument (Hitachi, Japan). TEM measurements were carried out using FEI (Tecnai G2 30 S-TWIN, USA) with an accelerating voltage of $100 \mathrm{kV}$. For TEM measurements, the sample solutions were coated on a formvar coated copper grid and dried in vacuum at room temperature before observation. Thermal analysis of the composites was performed with TA instruments (Differential Scanning Calorimetry 2920, Switzerland) instrument under nitrogen atmosphere. Rheological property of the conductive composite was measured using Modulated Compact Rheometre-150 Physica (Germany). Parallel plate sensor with a diameter of $50 \mathrm{~mm}$ and a gap size of $0.25 \mathrm{~mm}$ were used and measurements were done in dynamic oscillatory mode at $100^{\circ} \mathrm{C}$ (frequency range $0.001-1000 \mathrm{rad} / \mathrm{s}$ ). EMI SE of the prepared samples have been measured using a laboratory developed one-port coaxial sample holder backed by short on Vector network analyzer (VNA) Wiltron 37247B (Germany) in the desired frequency range. The return loss (RLin $\mathrm{dB}$ ) of the sample was measured on the calibrated VNA by connecting the one port sample holder at the test port without and with the sample. Half of this measured $\mathrm{RL}$ is the EMI SE of the sample in dBs.

\section{Results and discussion}

\subsection{Mechanism for the formation of 'percolated conductive composite, PVCPCN}

Percolated pattern of electrically conductive PVCPCN prepared by admicellar oxidative radical polymerization of $\mathrm{An}^{+} \mathrm{PDPSA}^{-}$in $\mathrm{PVC}$-clay dispersion using APS as initiator and is shown in Figure 1. Formation of 'porous template' was manifested from the studies made using SEM, AFM and TEM in combination with FTIR. FT-IR spectra of PANI, PVC-clay dispersion, PVC, PVCPCN and clay are shown in Figure 2, respectively. PANI showed characteristic bands at 1552 and $1483 \mathrm{~cm}^{-1}$ (stretching vibration of quinoid ring and benzenoid ring), $3100 \mathrm{~cm}^{-1}(\mathrm{~N}-\mathrm{H} \mathrm{str}), 2900$ and $2850 \mathrm{~cm}^{-1}(\mathrm{C}-$ $\mathrm{H} \mathrm{str}$ ), and $1297 \mathrm{~cm}^{-1}(\mathrm{C}-\mathrm{N})$. PVC exhibited charac- 


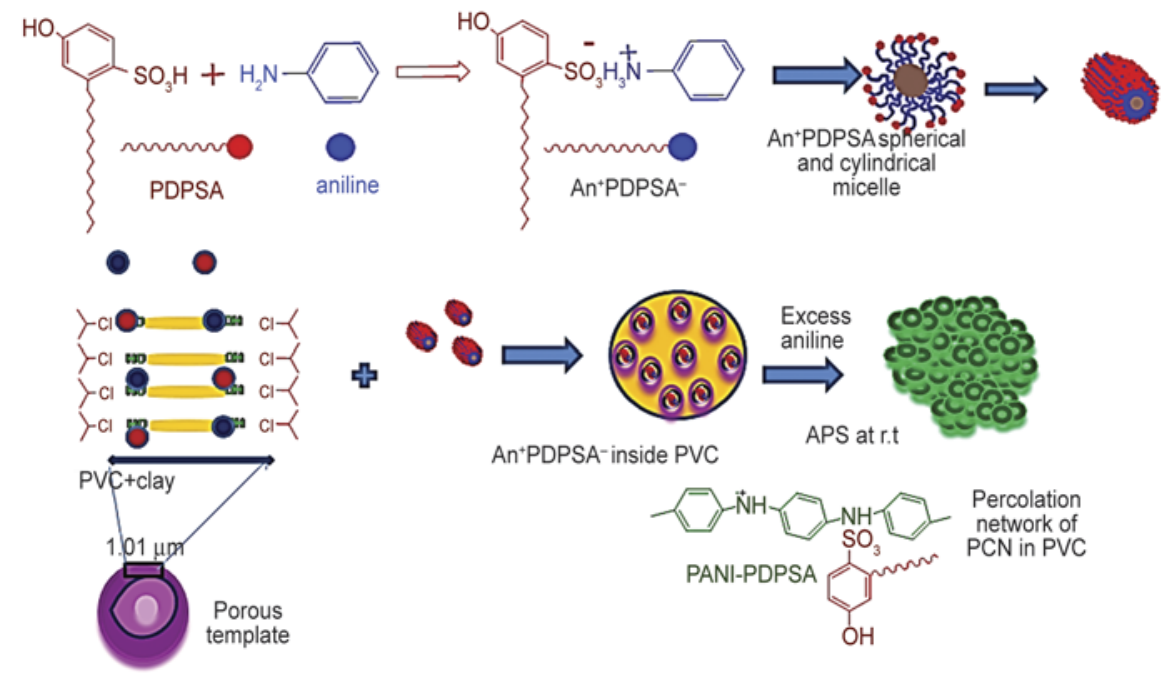

Figure 1. Preparation of conductive composite

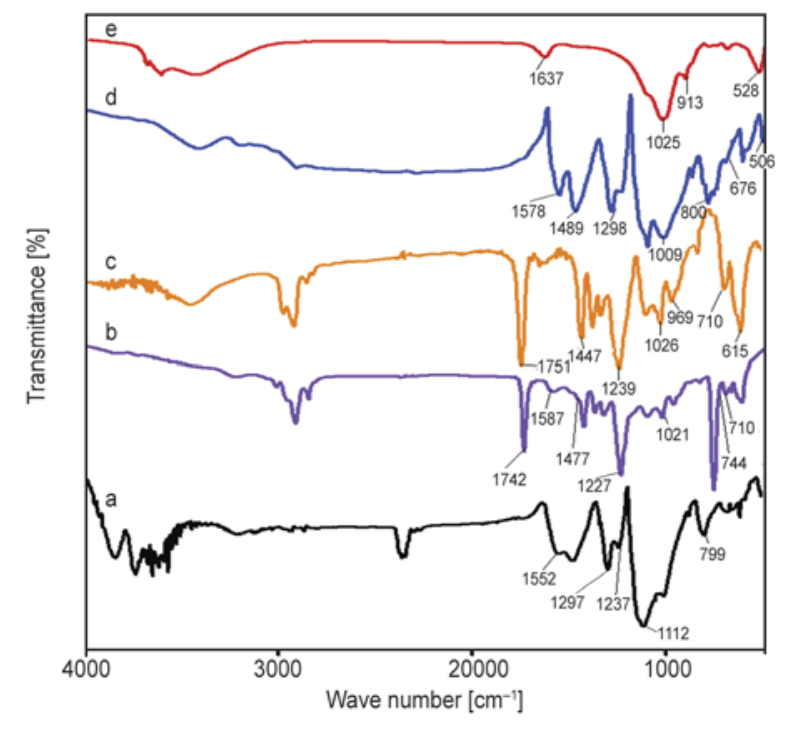

Figure 2. FT-IR spectra of (a) PANI, (b) PVC clay dispersion, (c) PVC, (d) PVCPCN, (e) clay

teristic bands at $1447 \mathrm{~cm}^{-1}\left(\mathrm{CH}_{2}\right), 1239 \mathrm{~cm}^{-1}(\mathrm{C}-\mathrm{H}$ of $\mathrm{CHCl}), 1026 \mathrm{~cm}^{-1}(\mathrm{C}-\mathrm{C}), 969 \mathrm{~cm}^{-1}\left(\mathrm{CH}_{2}\right.$ rocking) and $710,615 \mathrm{~cm}^{-1}(\mathrm{C}-\mathrm{Cl})$ [12]. Clay showed characteristic peaks at $1025 \mathrm{~cm}^{-1}$ [v (Si-O)], $913 \mathrm{~cm}^{-1}$ [v $(\mathrm{Al}-\mathrm{OH})]$ and $528 \mathrm{~cm}^{-1}[v(\mathrm{Si}-\mathrm{O}-\mathrm{Al})]$. However, the FTIR spectra of PVC-clay dispersion exhibited the bands at 1477, 1227, 1021, 744 and $710 \mathrm{~cm}^{-1}$. The observed shift in the bands of PVC-clay dispersion compared to the characteristic bands of PVC and clay revealed the presence of noncovalent interactions among clay and PVC moieties. These interactions are responsible for the formation of porous template. Microscopic analysis of PVC-clay dispersion exhibited almost uniform microporous shapes having pore diameter of $\sim 1.5 \mu \mathrm{m}$ ESEM and ordinary SEM images were shown in Figure $3 a$ and $3 b$, respectively. Dimension of the pore size and thickness were further confirmed by AFM studies and the corresponding image of the PVC-clay was shown in Figure 3c. The AFM image of a single pore is given in Figure $3 \mathrm{e}$ and its height profile is depicted in Figure 3d. Pore size of the template is measured to be $\sim 1.32 \mu \mathrm{m}$ which is almost matching with the observation from SEM analysis and wall thickness of the pore is measured as $\sim 100 \mathrm{~nm}$. The pore wall was formed by parallel stack of silicate layers and its aggregates through edge to edge association as reported earlier [23]. Further formation of porous template was confirmed by TEM analysis and the image of the same is given in Figure 4. Here also the image measured pore size of $\sim 1.3 \mu \mathrm{m}$ with well defined wall thickness of $98 \mathrm{~nm}$.

FTIR spectrum of PVCPCN exhibited bands at $1578,1489,1298,1009,800,676,506 \mathrm{~cm}^{-1}$ and shown in Figure 2 curve d. The observed shift in the positions of bands in PVCPCN compared to the characteristic bands of PANI, clay and PVC can be ascribed due to the formation of noncovalent interaction among the clay, PANI and PVC moieties. Thus, the various noncovalent and covalent interactions among the various entities present in clay, PANI and PVC are responsible for the formation of steady and uniform films.

The mechanism for the formation of steady and uniform conductive films can be explained by the results obtained from FTIR and morphological analysis. Initially, aniline combines with the amphiphilic dopant PDPSA to form $\mathrm{An}^{+} \mathrm{PDPSA}^{-}$by the acidbase reaction. Later they will self-assemble in water to form cylindrical micelles as shown in Figure 1. 

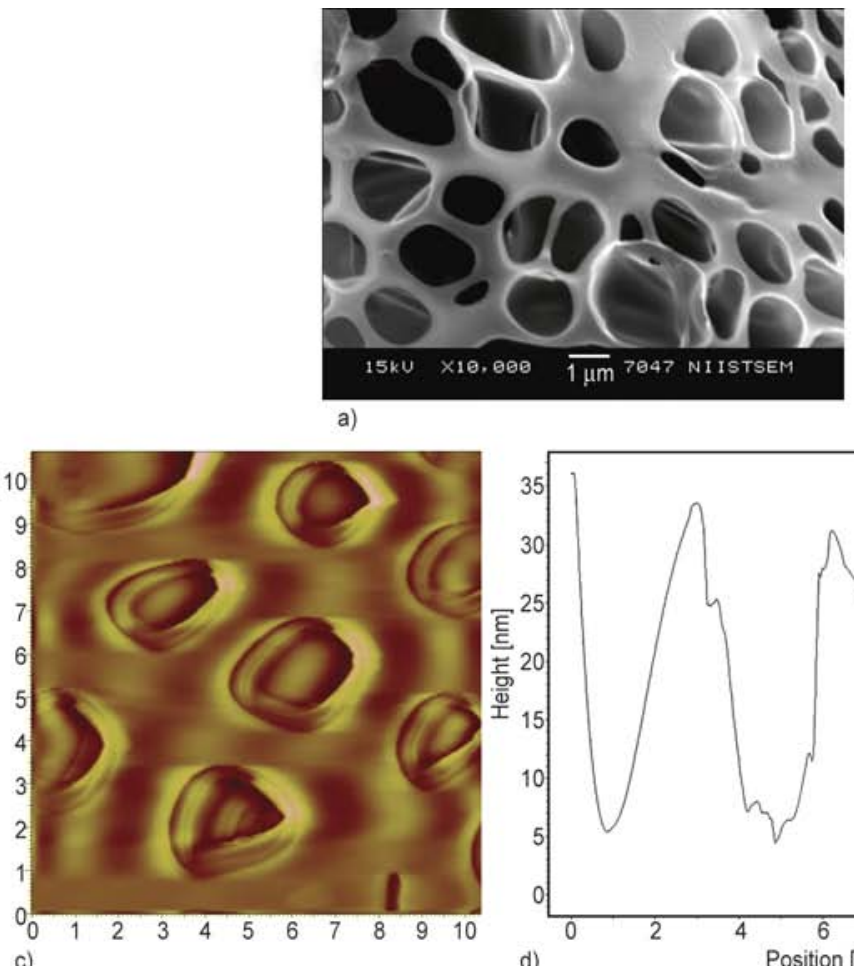

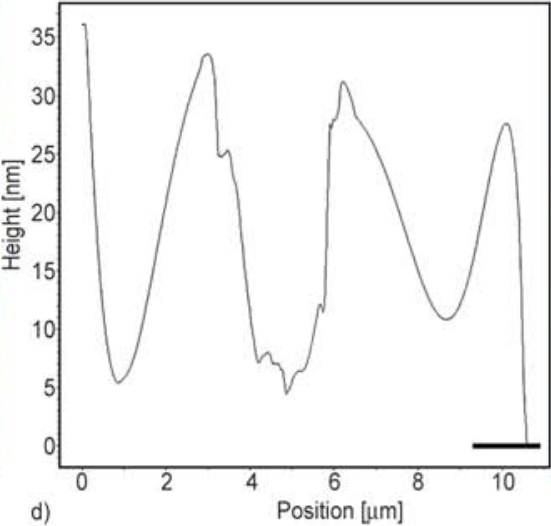

d)

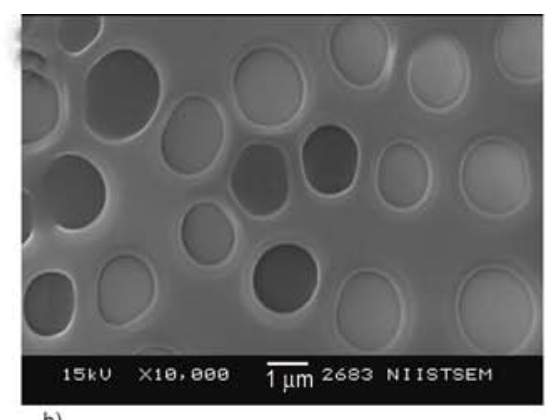

b)

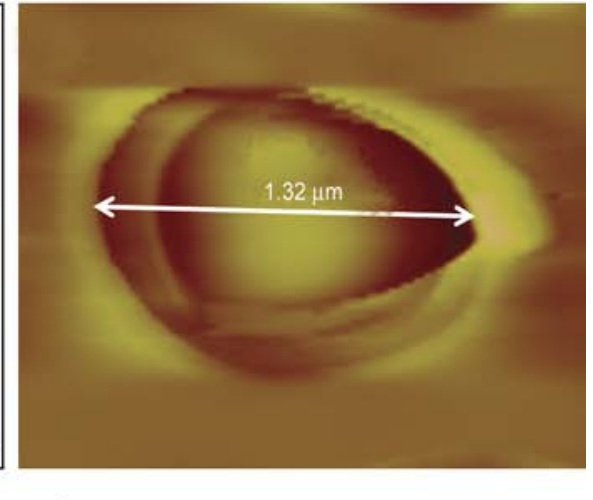

e)

Figure 3. SEM image of porous template (a) ESEM, (b) ordinary SEM, (c) AFM image of PVC-clay pores, (d) AFM profile of porous template, (e) AFM image of a single pore

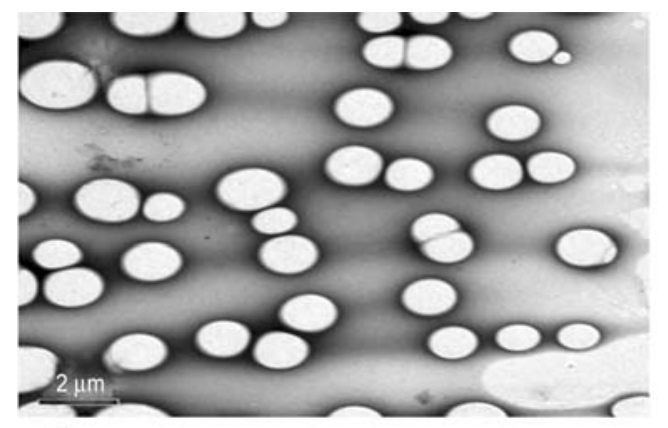

a)

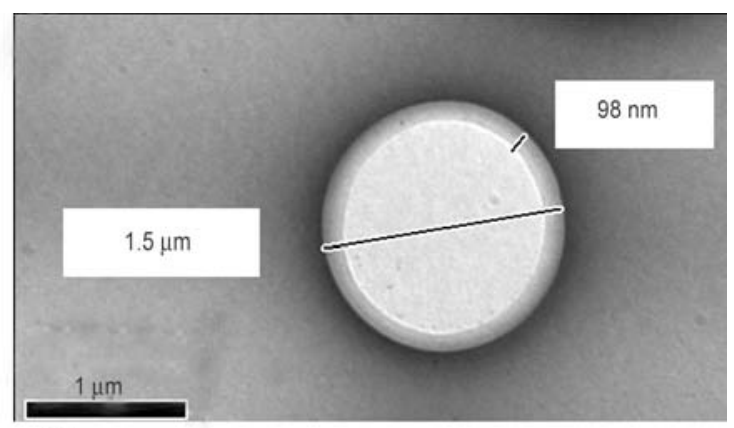

b)

Figure 4. TEM image of (a) porous templates of PVC-clay, (b) single pore

During agitation $\mathrm{An}^{+} \mathrm{PDPSA}^{-}$micelles present in the emulsion can be easily introduced into the hydrophilic pores present in PVC-clay dispersion through the driving force of interfacial attraction between the hydrophilic charges present in the walls of the pore towards the micelle. In the presence of excess aniline, some portion of the aniline will imbibe inside the cylindrical micelle and some portion will be retaining in the chloroform layer. In the presence of oxidative radical intiator APS, polymerization initiates inside the pore and propagates through the walls. Similar polymerization propagation process guided by the hydrophilic groups present in the hard template was reported earlier and it strengthens our observation [24-26]. As polymerization proceeds further, the various covalent and noncovalent interactions among clay tactoids, PVC and PANI become stronger and this may cause collapsing the walls of pores to form percolated network structure in PVCPCN. This mechanism is supported by the studies made by other researchers [27]. The AFM micrographs of PVCPCN are shown in Figure $5 \mathrm{a}$ (cast in glass plate) and Figure 5b (casted in HOPG plate). SEM picture of the same is given as Figure 5c. Both micrographs exhibited percolated wires of PCN (bright shade) in PVC matrix (dark shade) having micrometer in length and diameter of $\sim 20 \mathrm{~nm}$. The AFM height profiles of the same are shown in Figure 5d and 5e respectively. Topographical analysis showed that the heights of the PCN particles are in $\sim 5$ to $20 \mathrm{~nm}$ suggesting the formation of nanostructured conducting particles of 


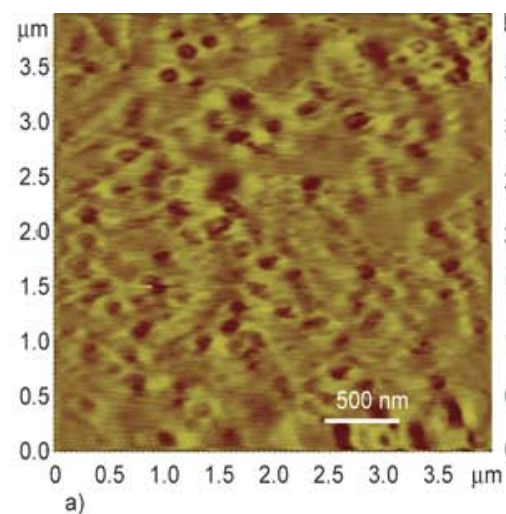

a)

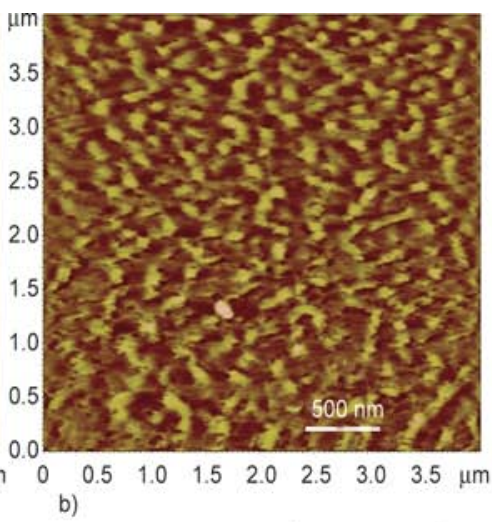

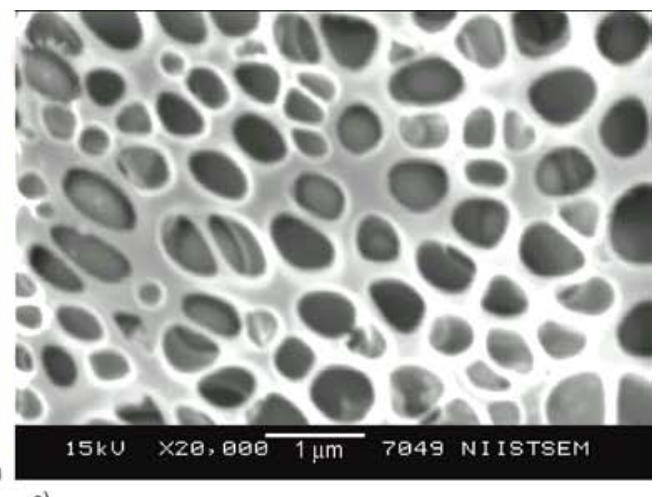

c)
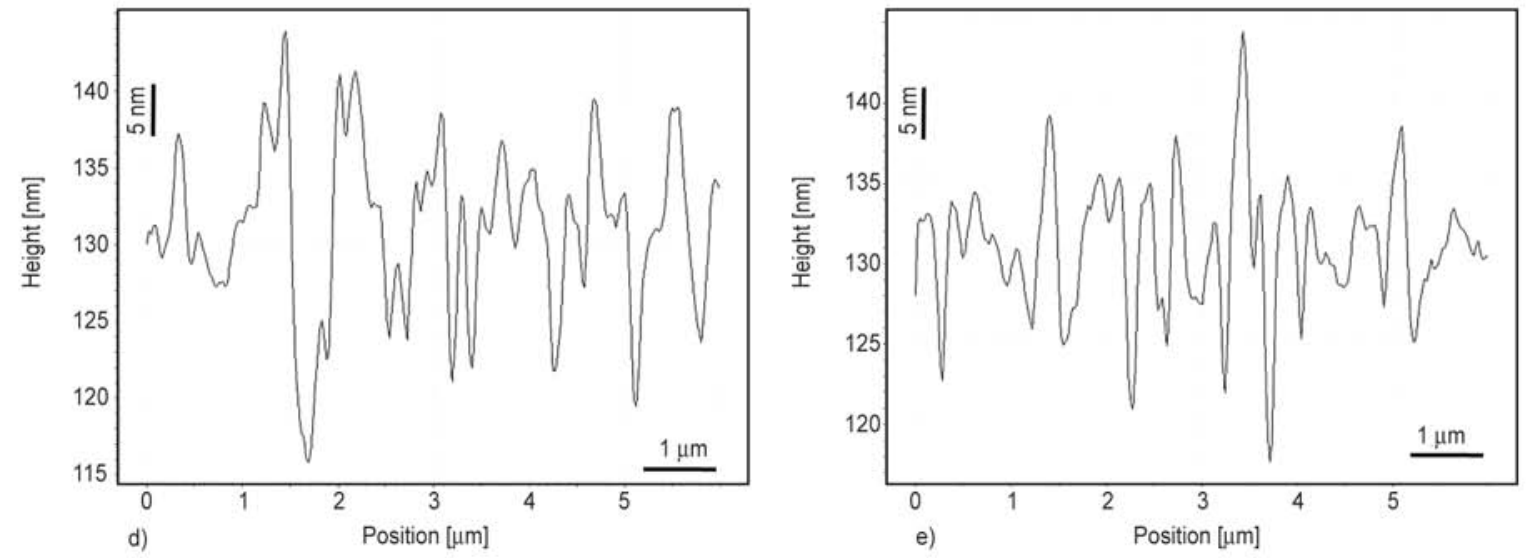

Figure 5. AFM micrographs of PVCPCN observed during the onset of percolation (a) casted in glass plate, (b) casted in HOPG substrate and (c) SEM image of PVCPCN (d, e) AFM height profile of PVCPCN during onset of polymerization casted in glass plate and HOPG substrate respectively

PCN in PVC matrix. The surface roughness of the film was measured to be $1.776 \mathrm{~nm}$. Based on the morphological and spectroscopic experimental evidence, a plausible mechanism for the formation of highly oriented percolated structures of nanowires of PCN in PVC is illustrated as per Figure 1.

\subsection{UV-Vis spectroscopy}

Electronic state of the conductive composite was manifested from UV-Vis spectroscopy. UV-vis spectra of PANI, PCN, PVCPN and PVCPCN are shown in Figure 6. PANI exists in the emeraldine salt state. PANI exhibited three peaks at (i) $340 \mathrm{~nm}$ corresponding to $\pi-\pi^{*}$ transition of benzenoid structure, (ii) $440 \mathrm{~nm}$ corresponding to the polaron band to $\pi *$ (iii) 700-900 nm corresponding to $\pi$-polaron bandpresent in the PANI chain. However, PCN and PVCPN exhibited a broad absorption maximum at $460 \mathrm{~nm}$ due to the merging of two initial peaks (330 and $460 \mathrm{~nm}$ ) and a second absorption maximum at $750 \mathrm{~nm}$. The absorption spectra of PVCPCN showed similar pattern with a red shift in the polaron band with a free carrier tail at $900 \mathrm{~nm}$. This red shift observed in the composites when compared to

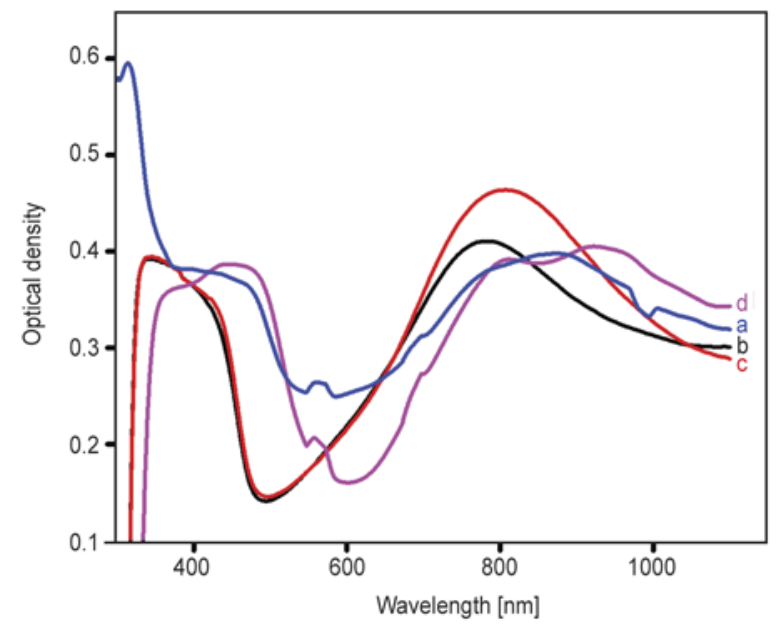

Figure 6. UV-visible spectra of (a) PANI, (b) PCN, (c) PVCPN, (d) PVCPCN

PVCPN is due to the formation of more number of delocalized charge carriers present in the polaron band.

\subsection{X-ray diffraction studies}

X-ray diffractograms of clay, PANI-PDPSA, PVCPN and PVCPCN were recorded using thin films of samples having $100 \mu \mathrm{m}$ thicknesses and are shown 


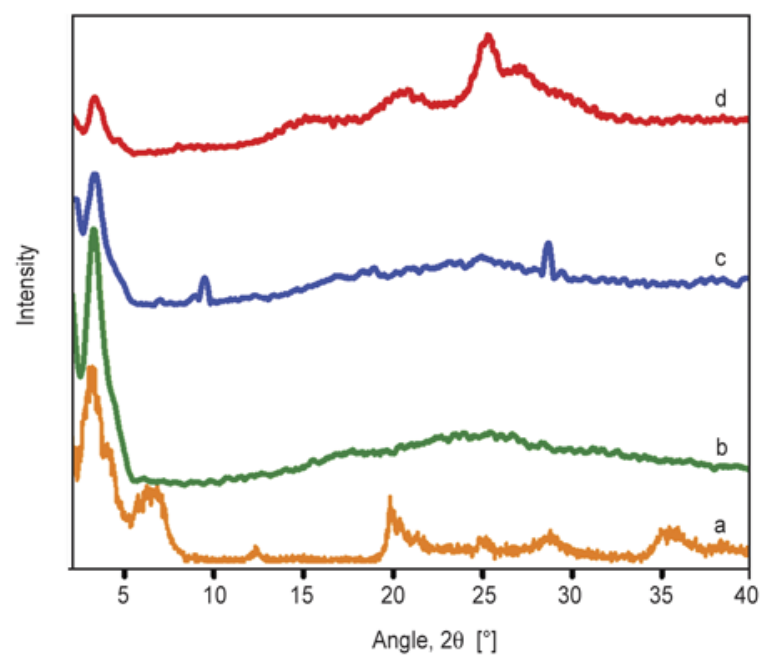

Figure 7. XRD plots of (a) clay, (b) PANI-PDPSA, (c) PVCPN, (d) PVCPCN

in Figure 7. Clay showed d001 basal spacing of $12.1 \AA$ at $2 \theta=6.7^{\circ}$ corresponding to the distance between the layers along the c-axis direction. PANI exhibited characteristic broad peak at $2 \theta=23.4^{\circ}$ and a sharp reflection at $2 \theta=3.4^{\circ}$ corresponding to the self assembled aggregated structure. PVCPN exhibited diffraction peaks at $2 \theta=3.3,9.4,28.6^{\circ}$ with d-spacing of $25.5,9.0,3.0 \AA$ respectively. In PVCPCN, the diffraction peak corresponding to the $\mathrm{d}_{001}$ plane of clay completely shifted to $2 \theta=3.3^{\circ}$ with d-spacing of $26.4 \AA$ and might have merged with the aggregated peak of self assembled PANIPDPSA.It exhibited peaks at broad peaks at 20.52, $25.22,27.26^{\circ}$ with $d$-spacing of $4.21,3.43$ and $3.18 \AA$, respectively.

\subsection{Electrical conductivity and EMI shielding efficiency}

Electrical conductivity measurement of the PVCPN and PVCPCN were done using thin films of uniform thickness and the values are depicted in Table 1. PANI-PDPSA exhibited conductivity of $3.5 \mathrm{~S} / \mathrm{cm}$. PTC of the conductive material in the composite was determined by plotting electrical conductivity measurements against the concentration of conductive material. It was observed that electrical conductivity exhibited a plateau beyond certain concentration and is considered as the onset of a conductive path in the matrix. This value depends upon the shape and size distribution of conductive particles in the polymer matrix and has been applied to describe electrical conductivity observations within various composites. For PVCPN, PTC is observed to be 7.5 weight percentage with conductivity $2.45 \cdot 10^{-2} \mathrm{~S} / \mathrm{cm}$ and that of PVCPCN showed PTC at 5 weight percentage with conductivity $4.26 \cdot 10^{-2} \mathrm{~S} / \mathrm{cm}$. Similar observations were made by other researchers [28]. Thus, the electrical conductivity measurement also substantiated the formation of more ordered conductive network in presence of clay. This observation is complimentary to the observations from SEM and AFM.

Effect of PVCPN and PVCPCN on EMI SE was studied and the details are showed in Table 1. It was observed that as the amount of conductive filler loading increased, EMI SE also showed a hike in the values. The EMI SE of conductive films of PVCPN containing PANI $5,7.5$ and $10 \%$ were measured to be 7.1, 8.2 and $14.8 \mathrm{~dB}$ respectively. EMI SE measurement of PVCPCN films containing conductive fillers of 2.5, 5, 7.5 and $10 \%$ exhibited EMI SE of 35.3, 56.766 and $73.2 \mathrm{~dB}$ respectively. The higher EMI SE value observed for PVCPCNs is attributed from the higher extent of attenuation favoured by the multiple reflection mechanism induced by the nano clay layers having high interfacial area [29]. Thus the films containing PCNs could attenuate electromagnetic radiation by two mechanisms of absorption and multiple reflections.

\subsection{DSC}

PVC showed a thermal transition at $75^{\circ} \mathrm{C}$ corresponding to the glass transition of PVC. PANI exhibited a broad endothermic transition at $106^{\circ} \mathrm{C}$ due to breaking of the intermolecular hydrogen bonding present in the bulk PANI. PVCPN exhibited a broad endothermic transition between $79-106^{\circ} \mathrm{C}$ which can be considered as the energy transition due to the noncovalent interaction among the various moieties present in PVCPN. But PVCPCN showed three transitions between $102-123^{\circ} \mathrm{C}$, which can be ascribed due to the unwinding of PCN chains through breaking the noncovalent interactions between clay tactoids and PVC.

\subsection{Rheology}

The presence of exfoliated nanoclay layers and the interaction between the conductive filler-host matrix was manifested from rheological property measurements. Loss modulus $\left(G^{\prime \prime}\right)$ and storage modulus $\left(G^{\prime}\right)$ were measured as a function of frequency at $100^{\circ} \mathrm{C}$ under angular frequency sweep of 0.001 to $1000 \mathrm{rad} / \mathrm{sec}$ at $5 \%$ strain. The $G^{\prime}$ is related to the 


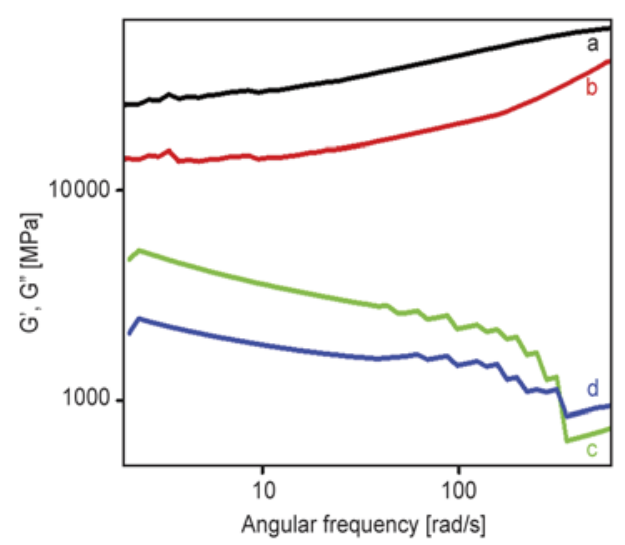

Figure 8. Variation of $G^{\prime}$ and $G^{\prime \prime}$ with angular frequency: (a) $G^{\prime}$ of PVCPCN (b) $G^{\prime \prime}$ of PVCPCN (c) $G^{\prime}$ of PVCPN and (d) $G^{\prime \prime}$ of PVCPN

ability of the material to store energy when an oscillatory force is applied to the specimen and the $G^{\prime \prime}$ is related to the ability to lose the energy. These properties were measured to examine the degree of entanglement in the conductive composite of PVCPCN. Variation of $G^{\prime}$ and $G^{\prime \prime}$ with angular frequency of PVCPN and PVCPCN are shown in Figure 8. Both exhibited distinctly different oscillatory responses. $G^{\prime}$ and $G^{\prime \prime}$ of PVCPCN is found to be greater than that of PVCPN. This could be due to the presence of entanglement induced by the percolated nanoaggregates present in PVCPCN [30, 31].

\section{Conclusions}

In summary, electrically conductive films with highly ordered percolated conductive network pattern (PVCPCN) were successfully prepared by selfassembly cum porous template based strategy. Here, the surfactant cum dopant, PDPSA derived from a low cost renewable resource based product could function as soft template and structure-directing agent. Thus the combination of self-assembly growth with hydrophilic porous template allows the formation of large scale percolated patterns of nanowires. This capability in retaining template without post processing is challenging in organic electronic devices. Moreover, property evaluation of this material exhibited excellent electrical conductivity and EMI SE which makes them a promising candidate for EMI/electrostatic dissipating matrix for high technological applications. Further, the proposed strategy can be exploited for the development of percolated patterns of nanostructured conductive molecules in other insulative matrices for the fabrication of nanoelectronic devices.

\section{Acknowledgements}

We thank the Indian Space Research Organization ISRO RESPOND (GAP 109439) programme and CSIR NWP-54 for their financial support. We are also thankful to Dr. Suresh Das, Director, NIIST, CSIR, TVM for all the encouragement and support and Dr. A. Ajayaghosh, NIIST, Trivandrum and Mr. M.R. Chandran, Kiran Mohan, Mr. P. Guruswamy, NIIST Trivandrum, for SEM, TEM and WAXRD analysis.

\section{References}

[1] Zhang Z., Wei Z., Wan M.: Nanostructures of polyaniline doped with inorganic acids. Macromolecules, 35, 5937-5942 (2002). DOI: $10.1021 / \mathrm{ma020199 \textrm {V }}$

[2] Jang J., Yoon H.: Facile fabrication of polypyrrole nanotubes using reverse microemulsion polymerization. Chemical Communications, 6, 720-721 (2003). DOI: $10.1039 / \mathrm{B} 211716 \mathrm{~A}$

[3] Shi L., Wu X., Lu L., Yang X., Wang X.: Molecular mechanism for formation of polyaniline lamella from a lyotropic liquid crystal: An NMR study. Journal of Physical Chemistry B, 113, 2725-2733 (2009). DOI: $10.1021 / j p 9002824$

[4] Rabatic B. M., Pralle M. U., Tew G. N., Stupp S. I.: Nanostructured semiconductors templated by cholesteryl-oligo(ethylene oxide) amphiphiles. Chemistry of Materials, 15, 1249-1255 (2003).

DOI: $10.1021 / \mathrm{cm} 020899 \mathrm{e}$

[5] Hong B. H., Lee J. Y., Lee C-W., Kim J. C., Bae S. C., Kim K. S.: Self-assembled arrays of organic nanotubes with infinitely long one-dimensional H-bond chains. Journal of the American Chemical Society, 123, 10748-10749 (2001). DOI: $10.1021 / \mathrm{ja0} 16526 \mathrm{~g}$

[6] Collins S. K., Yap G. P. A., Fallis A. G.: The synthesis of a novel strained diyneparacyclophane and its dimer by metal-mediated coupling. Angewandte Chemie International Edition, 39, 385-388 (2000).

DOI: 10.1002/(SICI)1521-3773(20000117)39:2<385:: AID-ANIE385>3.0.CO;2-I

[7] Qiu H., Zhai J., Li S., Jiang L., Wan M.: Oriented growth of self-assembled polyaniline nanowire arrays using a novel method. Advanced Functional Materials, 13, 925-928 (2003).

DOI: $10.1002 / \mathrm{adfm} .200304366$

[8] Carswell A. D. W., O’Rea E. A., Grady B. P.: Adsorbed surfactants as templates for the synthesis of morphologically controlled polyaniline and polypyrrole nanostructures on flat surfaces: From spheres to wires to flat films. Journal of the American Chemical Society, 125, 14793-14800 (2003).

DOI: $10.1021 / \mathrm{ja} 0365983$

[9] Jadhav A. S., Maldar N. N., Shinde B. M., Vernekar S. P.: Synthesis and characterization of silicon-containing polyamides from aromatic sulfone ether diamines and aromatic organosilicon diacid chlorides. Journal of Polymer Science Part A: Polymer Chemistry, 37, 147-153 (1991).

DOI: $10.1002 /$ pola.1991.080290202 
[10] Zhang X., Zhang J., Liu Z., Robinson C.: Inorganic/ organic mesostructure directed synthesis of wire/ribbon-like polypyrrole nanostructures. Chemical Communications, 16, 1852-1853 (2004).

DOI: $10.1039 / \mathrm{B} 405255 \mathrm{~B}$

[11] Abdou M. S. A., Xie Z. W., Leung A. M., Holdcroft S.: Laser, direct-write microlithography of soluble polythiophenes. Synthetic Metals, 52, 159-170 (1992).

DOI: 10.1016/0379-6779(92)90304-2

[12] Babu S. S., Mahesh S., Kartha K. K., Ajayaghosh A.: Solvent-directed self-assembly of $\pi$ gelators to hierarchical macroporous structures and aligned fiber bundles. Chemistry - An Asian Journal, 4, 824-829 (2009). DOI: 10.1002/asia.200900145

[13] Malik S., Roizard D., Guenet J-M.: Multiporous material from fibrillar syndiotactic polystyrene intercalates. Macromolecules, 39, 5957-5959 (2006).

DOI: $10.1021 / \mathrm{ma} 060770 \mathrm{~g}$

[14] Dasgupta D., Manna S., Malik S., Rochas C., Guenet J. M., Nandi A. K.: Thermodynamic structural and morphological investigation of poly(vinylidene fluoride)-camphor systems, preparing porous gels from a solid solvent. Macromolecules, 38, 5602-5608 (2005). DOI: $10.1021 / \mathrm{ma} 050582 \mathrm{a}$

[15] Pongprayoon T., Yanumet N., O'Rear E. A.: Admicellar polymerization of styrene on cotton. Journal of Colloid and Interface Science, 249, 227-234 (2002). DOI: $10.1006 /$ jcis. 2002.8230

[16] Okada A., Usuki A.: Twenty years of polymer-clay nanocomposites. Macromolecular Materials and Engineering, 291, 1449-1476 (2006).

DOI: $10.1002 /$ mame. 200600260

[17] Tjong S. C.: Structural and mechanical properties of polymer nanocomposites. Materials Science and Engineering R: Reports, 53, 73-197 (2006).

DOI: $10.1016 / \mathrm{j} . \mathrm{mser} .2006 .06 .001$

[18] Ren J., Krishnamoorti R.: Nonlinear viscoelastic properties of layered-silicate-based intercalated nanocomposites. Macromolecules, 36, 4443-4451 (2003). DOI: $10.1021 / \mathrm{ma} 020412 \mathrm{n}$

[19] Haraguchi K., Ebato M., Takehisa T.: Polymer-clay nanocomposites exhibiting abnormal necking phenomena accompanied by extremely large reversible elongations and excellent transparency. Advanced Materials, 18, 2250-2254 (2006). DOI: $10.1002 /$ adma.200600143

[20] Toombes G. E. S., Mahajan S., Thomas M., Du P., Tate M. W., Gruner S. M., Wiesner U.: Hexagonally patterned lamellar morphology in $\mathrm{ABC}$ triblock copolymer/aluminosilicate nanocomposites. Chemistry of Materials, 20, 3278-3287 (2008). DOI: $10.1021 / \mathrm{cm} 702842 \mathrm{~b}$
[21] Negrete-Herrera N., Putaux J-L., David L., De Haas F., Bourgeat-Lami E.: Polymer/laponite composite LATEXES: Particle morphology, film microstructure, and properties. Macromolecular Rapid Communications, 28, 1567-1573 (2007).

DOI: $10.1002 /$ marc. 200700212

[22] Sudha J. D., Reena V. L., Pavithran C.: Facile green strategy for micro/nano structured conducting polyaniline-clay nanocomposite via template polymerization using amphiphilic dopant, 3-pentadecyl phenol 4-sulphonic acid. Journal of Polymer Science Part B: Polymer Physics, 45, 2664-2673 (2007).

DOI: $10.1002 /$ polb.21273

[23] Kieffer J.: Mechanical degradation and viscous dissipation in $\mathrm{B}_{2} \mathrm{O}_{3}$. Physical Review B, 50, 17-29 (1994). DOI: 10.1103/PhysRevB.50.17

[24] Sudha J. D., Sivakala S.: Conducting polystyrene/ polyaniline blend through template-assisted emulsion polymerization. Colloid and Polymer Science, 287, 1347-1354 (2009).

DOI: $10.1007 / \mathrm{s} 00396-009-2101-5$

[25] Nam P. H., Maiti P., Okamoto M., Kotaka T., Hasegawa N., Usuki A.: A hierarchical structure and properties of intercalated polypropylene/clay nanocomposites. Polymer, 42, 9633-9640 (2001).

DOI: 10.1016/S0032-3861(01)00512-2

[26] Nair B. P., Pavithran C., Sudha J. D., Prasad V. S.: Microvesicles through self-assembly of polystyreneclay nanocomposite. Langmuir, 26, 1431-1434 (2010). DOI: $10.1021 / 1 \mathrm{la903360 \textrm {e }}$

[27] Pielichowski K.: Thermal degradation of poly(vinyl chloride)/polyaniline conducting blends. Journal of Thermal Analysis and Calorimetry, 54, 171-175 (1998). DOI: $10.1023 / \mathrm{A}: 1010129205138$

[28] Conn C., Booth N., Unsworth J.: Preparation of a flexible polyaniline-pvc composite. Advanced Materials, 7, 790-792 (1995).

DOI: $10.1002 / \mathrm{adma} .19950070905$

[29] Yang S., Lozano K., Lomeli A., Foltz H. D., Jones R.: Electromagnetic interference shielding effectiveness of carbon nanofiber/LCP composites. Composites Part A: Applied Science and Manufacturing, 36, 691-697 (2005).

DOI: 10.1016/j.compositesa.2004.07.009

[30] Filippone G., Dintcheva N. T., Acierno D., La Mantia F. P.: The role of organoclay in promoting co-continuous morphology in high-density poly(ethylene)/poly (amide) 6 blends. Polymer, 49, 1312-1322 (2008). DOI: $10.1016 /$ j.polymer.2008.01.045

[31] Wang Y., Jing X.: Intrinsically conducting polymers for electromagnetic interference shielding. Polymers for Advanced Technologies, 16, 344-351 (2005). DOI: $10.1002 /$ pat.589 